\title{
A INTERFERÊNCIA DOS ASTROS EM SUA VIDA
}

\author{
Tarik Rezende de Azevedo ${ }^{1}$
}

Resumo: Discute-se, à luz de conhecimentos básicos de astronomia e de física clássica, se, como e quais astros interferem de forma expressiva em processos do planeta Terra na escala de uma vida humana. Este é um ensaio de caráter didático baseado em conteúdo de uma aula efetivamente ministrada em curso de Licenciatura em Geografia.

Palavras-chave: Ensino fundamental; Geografia; Astronomia; Gravitação.

\section{Introdução}

Seja como professor do ensino fundamental e médio, como professor universitário ou ministrando cursos de capacitação de professores, confronto-me freqüentemente com um universo de questões que, quero acreditar, faça parte do imaginário de boa parte das pessoas. Dizem respeito ao binômio astronomia e astrologia. Que alunos misturem conhecimentos díspares e construam concepções muitas vezes curiosíssimas sobre seu lugar no universo e sua relação com o mesmo não espanta. Esta é uma das funções do professor, ajudar o aluno a separar o joio do trigo. 0 que realmente preocupa é que, muitas vezes, os próprios professores de geografia, ou mesmo de ciências, não sejam capazes de elencar ao menos um argumento ou raciocínio convincente. Pudera! Conhecimentos básicos (ou mínimos) de astronomia são fundamentais à formação do professor de geografia e também do cidadão.

Como podemos fazer alguém que acredita que sua história individual é regida por astros a milhares e milhares de anos-luz, que a história é uma construção coletiva, social, que não há um destino mas um devir em eterna construção (SAGAN, 1985)? Como sensibilizar o futuro cidadão às questões ambientais se ingenuamente acredita que no futuro, uma vez devastada a superfície da Terra, nossos descendentes colonizarão outros planetas e viajarão pelo universo em gigantescas arcas de Noé tecnológicas (MOURÃO, 1982)? Como convencer alguém, que sonha com um contato imediato de terceiro grau (DANIKEN, 1970), que somos, antes de tudo, prisioneiros da película superficial de nosso planeta, e que dela dependerão, além de nós, todas as gerações futuras?

\section{Do ponto de vista estritamente físico}

Muitos desmerecem a astrologia por não ser conhecimento de caráter científico. Outros dizem que sendo a ciência muito limitada, não se descobriu ainda a possivel relação entre a configuração ou posição dos astros e a história individual, do que também discordamos. Não só conhecemos quais sejam estas interaç̃oes, como qualquer aluno ao termo do ensino médio é (ou deveria ser) capaz de determinar sua intensidade e estabelecer comparações muito elucidativas (BRONOWSKI, 1983).

A interação à distância implica considerar que a possivel interferência seja derivada de algum tipo de relação física entre seu corpo e determinado astro. Pois bem, na ciência só se conhecem três tipos de interação à distância (que não dependa de meio material para sua propagação no espaço): (1) a força gravitacional, (2) a força magnética e (3) a força elétrica. $\mathrm{Na}$ verdade, quase todas as outras forças que conhecemos, desconsiderando as próprias da escala subatômica, podem ser reduzidas a estas três, embora não seja um procedimento muito prático para a investigação empírica. Por outro lado, a força elétrica e a força magnética são tratadas hoje como uma única força e consideradas como aspectos de uma mesma entidade física (HAWKING, 2001).

A luz solar é a fonte energética da quase totalidade dos processos bioquímicos da superfície terrestre e dos processos da máquina geomorfológica, sobretudo dos processos atmosféricos, hidrológicos e pedogenéticos (BLOOM,1970). A luz solar nada mais é que uma monumental perturbação, ou uma emaranhada mescla de oscilações no campo eletromagnético próximo à Terra. Portanto, não há dúvida quanto à influência do astro Sol em sua vida. Sem ele você simplesmente não existiria.

A distância da Terra ao Sol não é constante, mas, para os raciocínios que seguem, dizer que está a cerca de 150 milhões de quilômetros é uma aproximação razoável. Esta é uma distância

${ }_{1}$ Prof. Dr. Departamento de Geografia/ FFLCH/USP 
consideravelmente grande para qualquer comparação com as distâncias às quais estamos acostumados no cotidiano (ASSIMOV, 1986). No entanto, é muito, mas muito pequena em relação à distância a outras estrelas. A velocidade da luz é de 300 mil quilômetros por segundo. Portanto, a luz chega à Terra depois de pouco mais de oito minutos que foi emanada da superfície do Sol. Por isso dizemos que o Sol está à distância de cerca de oito minutos-luz da Terra. Isto significa que, quando dizemos que 0 Sol está em tal ponto do céu, na verdade estamos dizendo que ele estava neste lugar há oito minutos e pouco.

Alpha-Centauri é a estrela mais próxima da Terra tal como as vemos no céu noturno. Ela é a estrela mais brilhante ${ }^{2}$ da Constelação do Centauro. A distância é tão grande que não é muito prático expressá-la em quilômetros. Dizemos que Alpha Centauri está a 4,5 anos-luz da Terra, ou seja, a luz emanada dela chega na Terra depois de quatro anos e meio (SAGAN, 1986).

Alpha Centauri tem mais ou menos o mesmo tamanho e massa que o nosso Sol (SAGAN, 1986). Se considerarmos a estrela como uma fonte pontual de luz, podemos afirmar que a intensidade desta decresce com o quadrado da distância. Ou seja, se o nosso Sol estivesse no lugar onde está Alpha Centauri, a intensidade da insolação sobre a Terra seria menor cerca de 4 bilhões de vezes.

Realmente é difícil compreender o que significa a intensidade de uma fonte de luz ser menor que a de outra 4 bilhões de vezes. Comparemos com outras fontes de luz menos intensas. Um Led é aquele diodo luminescente que acende no painel do computador quando acessamos o disco. A intensidade da luz emitida por um Led, na distância que estamos normalmente sentados diante do computador, é mais de cinqüenta vezes maior que a de Alpha Centauri. Se a interação eletromagnética entre seu corpo e a estrela mais próxima depois do Sol, ou mesmo todas as outras, for significativamente importante, 0 apagar e acender de todos os bilhões de Leds em funcionamento no mundo neste instante deve estar causando a maior das revoluções em seu organismo. 0 simples apagar ou acender de uma lâmpada de $100 \mathrm{Wh}$, que emana o equivalente à luz que chegaria à Terra proveniente de cinco milhões de estrelas como Sirius, já dá o que pensar. Toda a luz proveniente de estrelas visíveis, e recebida pela Terra em um ano, equivale à energia emanada por uma vela (SAGAN, 1986).

Com isto acreditamos ter descartado a hipótese de que a interação eletromagnética entre seu corpo e as estrelas seja realmente substancial. Admitindo que seja, o que ocorre com a luz aqui na superfície da Terra concorre com esta interação estelar com tamanha magnitude que, aquela possivel interferência passa a ser insustentável ou, no mínimo, absolutamente desprezível. Assim, olhar sobre o rosto de outra pessoa, o brilho de um olho, mesmo do ponto de vista estreitamente físico, é muito mais significativo que a luz de qualquer estrela que não o sol.

Sobra apenas a interação gravitacional. Esta força também decresce com o quadrado da distância, conforme a genial proposição de Newton, que todos os alunos do ensino médio aprendem, ou deveriam (BRODY e BRODY, 1999). Sirius é a próxima estrela mais próxima da Terra depois de Alpha Centauri. Se você tiver uns 60 quilogramas de massa, a força gravitacional entre seu corpo e Sirius é cerca de 4 trilhonésios de Newton. A interação entre seu corpo e a Terra é de cerca de 580 Newton. Vamos estabelecer algumas comparações que ajudam a compreender como a força gravitacional de Sirius sobre seu corpo é desprezível.

Uma moeda de $\mathrm{R} \$ 1,00$ tem exatos 5 gramas. Numa distância de um metro exerce força gravitacional seis vezes maior que Sirius. Quando você está andando numa rua movimentada, as centenas de moedinhas nos bolsos e bolsas das pessoas que cruzam contigo, interagem com seu corpo de forma mais intensa que todas as estrelas juntas.

Imagine uma pessoa que venha caminhando em sua direção. Quando ela está a trezentos e poucos metros, a interação gravitacional entre ela e você já é maior que a exercida por Sirius. Quando está a um metro de distância esta interação gravitacional é, cerca de cem mil vezes mais intensa que em relação à estrela (Fig. 1). Ou seja, a presença de outra pessoa interfere muito mais na sua vida, mesmo do ponto de vista estritamente físico e gravitacional, que todas as estrelas que possamos ver.

Podemos considerar um exemplo mais bucólico. Um pombo a vinte metros de distância de seu corpo troca contigo uma força gravitacional quatro vezes maior que Sirius. Quando estamos sentados calmamente num pôr do Sol esperando surgirem as primeiras estrelas, as revoadas de pássaros, 0

\footnotetext{
${ }^{2}$ As estrelas visíveis a olho nu da superfície da Terra são ordenadas pelo brilho aparente dentro da constelação à que "pertencem". Esta ordem é convencionalmente associada ao alfabeto grego. Assim, ao invés de dizer a primeira estrela mais brilhante, a segunda estrela mais brilhante, dizemos: Alpha, Beta, e assim sucessivamente.
} 


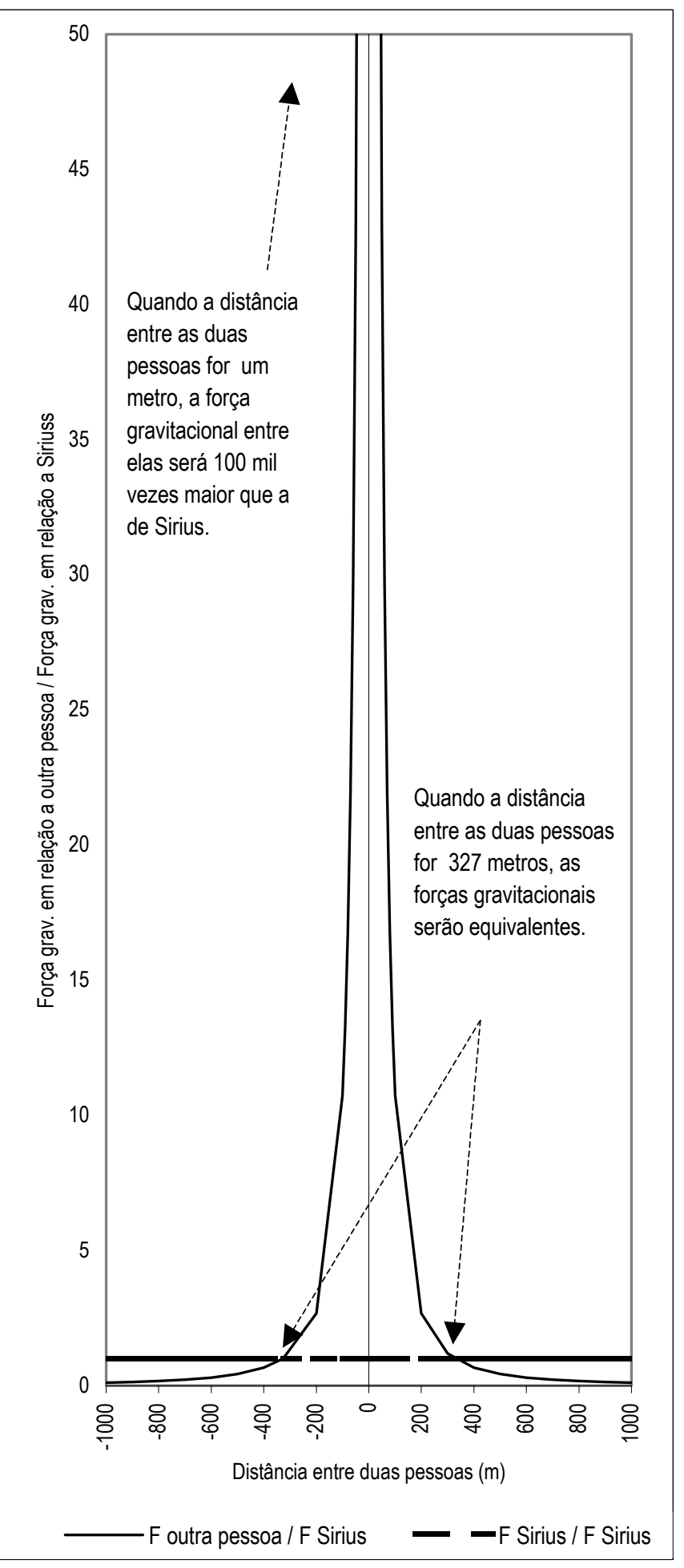

Figura 1 Força gravitacional entre duas pessoas de $80 \mathrm{~kg}$, comparada com a força entre cada uma delas e a estrela Sirius.

balançar das folhas das árvores e os movimentos do ar estão deformando o campo gravitacional à nossa volta de forma imperceptível, mesmo instrumentalmente.

No entanto, estas variações são incomensuravelmente maiores que as variações devido às estrelas. Sobretudo porque na escala temporal de uma vida humana, ou mesmo de muitas gerações, as mudanças de posição dos astros além do nosso sistema solar são imperceptíveis. 0 argumento de que o céu noturno vai lentamente variando ao longo do ano não se aplica neste caso, pois a variação da distância é absolutamente desprezível. Não importa se estamos de costas, de frente, de pé ou de ponta-cabeça em relação à estrela, na prática, a força é a mesma, além de ser minúscula.

Pois bem, os astros além do sistema solar foram descartados, mas os outros astros do sistema solar estão bem mais próximos. O Sol e a Lua interagem gravitacionalmente com os corpos da Terra de forma facilmente perceptível. Desde tempos imemoriais a humanidade relaciona o fenômeno das marés à posição do sol e da Lua em relação à Terra. Tanto que dizemos "maré solar" e "maré lunar". O que se descobriu depois é que 0 fenômeno da maré também ocorre na atmosfera e na litosfera. $A$ pressão atmosférica sobre seu corpo aumenta e diminui duas vezes por dia e por isso ocorrem dois ciclos diários de regulação interna do organismo para compensar. A superfície sólida, incluindo você e tudo mais, sobe e desce duas vezes por dia cerca de trinta centímetros. A maré vista na praia apenas é uma parte deste ritmo, e se deve ao fato da compressibilidade e mobilidade da água ser maior que a dos materiais sólidos (BLOOM, 1970). Existem centenas de ritmos naturais conhecidos (registrados e estudados) em fase com as marés. Quase todos são biológicos. Alguns são até curiosos. A sabedoria popular sugere que há "Lua certa" para cortar bambu para que, depois de seco, não rache. $\mathrm{Na}$ verdade a pesquisa sistemática do fenômeno revelou que, há "maré certa" para cortar o bambu, que, do ponto de vista prático, pode ser reduzido a "Lua certa" (CADOGAN, 1985).

Além dos ritmos relacionados à variação das forças gravitacionais do sistema Sol-Terra-Lua, existem ritmos relacionados à variação da interação eletromagnética neste mesmo sistema. O mais óbvio é o ciclo diário de sono e vigília, que o faz procurar sua cama todos os dias. No entanto, existem milhares de outros ritmos conhecidos, relacionados, sobretudo à variação da insolação ao longo do ano solar. Inúmeras adaptações reprodutivas e fisiológicas dos seres vivos em função das estações do ano são auto-evidentes.

Curiosamente, não é apenas a variação da insolação que pode ser relacionada aos ritmos terrestres. O luar tem intensidade muito menor que a insolação, mas incomensuravelmente maior 
que a da soma de todas as estrelas. 0 aparelho visual de quase todos os animais é capaz de funcionar sob esta pálida luz esbranquiçada. A pesca noturna, por exemplo, é regida há milênios pelo ritmo do luar. 0 ciclo reprodutivo de inumeráveis animais, de pequenos vermes ou insetos a mamíferos, coincide com o ritmo do luar.

Portanto, não há dúvidas de que o astro Lua, além do astro Sol, interfere de inúmeras formas em sua vida e em tudo o que ocorre na superfície da Terra, dos dois pontos de vista, gravitacional e eletromagnético. Mas, e os outros planetas e luas do sistema solar? Só podemos observar a olho nu os cinco planetas mais próximos. Sua luz é tão pálida que normalmente os confundimos com as estrelas. O que foi dito para a possível interação eletromagnética entre você e as estrelas também se aplica no caso dos planetas.

Na Tab. 1 você pode comparar a força gravitacional média de um corpo com $80 \mathrm{~kg}$ em relação ao sol, à Lua, aos planetas e às duas estrelas mais próximas (ordenadas de acordo com a intensidade). Para facilitar, comparemos com a força exercida pela Lua (nas duas últimas colunas). A força gravitacional de Júpiter sobre esse corpo de $80 \mathrm{~kg}$ é cerca de cem vezes menor que a da Lua, e a de Vênus é cerca de 176 vezes menor. Ou seja, é bastante provável que exista uma discreta "maré jupteriana" e outra "venusiana" na Terra. No entanto, embora seja possível perceber a interferência de Júpiter e Vênus na órbita terrestre, não se encontrou ainda nenhum ritmo biológico relacionado explicitamente à pequena, mas instrumentalmente perceptível, interferência gravitacional dos dois planetas. Nem mesmo nas marés foi possível distinguir, pelo menos até o presente, principalmente porque outros fenômenos, como o vento e as correntes marinhas, introduzem uma extrema complexidade neste tipo de investigação.

Tabela $1 \mathrm{~A}$ força gravitacional entre a massa de um corpo de $80 \mathrm{~kg}$ na Terra e a massa dos astros.

\begin{tabular}{|c|c|c|c|c|c|}
\hline $\begin{array}{c}\text { Astro } \\
\text { (nome) }\end{array}$ & $\begin{array}{c}\text { Massa do Corpo } \\
(\mathrm{Kg})\end{array}$ & $\begin{array}{l}\text { Distância } \\
(\mathrm{m})\end{array}$ & $\begin{array}{c}\text { Força Gravitacional } \\
\text { (N) }\end{array}$ & $\begin{array}{c}\text { Proporção } \\
\text { F astro / F Lua }\end{array}$ & $\begin{array}{c}\text { Proporção } \\
\text { F Lua / F astro }\end{array}$ \\
\hline Terra & $5,975 \times 10^{24}$ & $6,38 \times 1006$ & $7,84 \times 10^{+2}$ & $295.329,9$ & 0,0000034 \\
\hline Sol & $1,989 \times 10^{30}$ & $1,50 \times 10^{11}$ & $4,72 \times 10^{-1}$ & 177,8 & 0,0056 \\
\hline Lua & $7,349 \times 10^{22}$ & $3,84 \times 1008$ & $2,66 \times 10^{-3}$ & 1,0 & 1,0 \\
\hline Júpiter & $1,899 \times 10^{27}$ & $6,30 \times 10^{11}$ & $2,55 \times 10^{-5}$ & 0,0096 & 104 \\
\hline Vênus & $4,870 \times 1024$ & $4,15 \times 1010$ & $1,51 \times 10^{-5}$ & 0,00568 & 176 \\
\hline Saturno & $5,688 \times 10^{26}$ & $1,28 \times 10^{12}$ & $1,85 \times 10^{-6}$ & 0,000697 & 1.434 \\
\hline Marte & $6,393 \times 10^{23}$ & $7,85 \times 10^{10}$ & $5,53 \times 10^{-7}$ & 0,00020842 & 4.798 \\
\hline Mercúrio & $3,286 \times 10^{23}$ & $9,19 \times 10^{10}$ & $2,08 \times 10^{-7}$ & 0,000078220 & 12.784 \\
\hline Urano & $8,664 \times 10^{25}$ & $2,73 \times 10^{12}$ & $6,22 \times 10^{-8}$ & 0,0000234327 & 42.675 \\
\hline Netuno & $1,028 \times 10^{26}$ & $4,36 \times 1012$ & $2,89 \times 10^{-8}$ & 0,0000108828 & 91.888 \\
\hline Alpha Centauri & $2,148 \times 10^{30}$ & $4,17 \times 10^{16}$ & $6,61 \times 10^{-12}$ & 0,0000000025 & 401.752 .647 \\
\hline Sirius & $4,973 \times 10^{30}$ & $8,17 \times 10^{16}$ & $3,98 \times 10^{-12}$ & 0,0000000015 & 667.665 .188 \\
\hline Plutão & $1,494 \times 10^{22}$ & $5,81 \times 10^{12}$ & $2,36 \times 10^{-12}$ & 0,0000000009 & 1.123 .601 .468 \\
\hline
\end{tabular}

Seguindo o mesmo raciocínio, temos Saturno e Marte. Neste caso ocorre um novo salto de escala, e as forças gravitacionais que exercem sobre o corpo são da ordem de alguns milhares de vezes menor que a da Lua. Não é preciso estender a argumentação, suas marés são ainda mais hipotéticas e não percebidas instrumentalmente na superfície terrestre. Daí em diante, há Mercúrio, Urano e Netuno, e novo salto de escala. Finalmente, em direção ao minimesimal, verifique que a interação gravitacional entre o corpo e Plutão é menor que entre ele e Sirius. Apesar deste astro estar muito mais próximo que aquela estrela, sua massa é muito menor.

Portanto, do ponto de vista físico, podemos dizer que três astros certamente influenciam sua vida: a Terra, o Sol e a Lua ${ }^{3}$. Além destes três, do ponto de vista hipotético, Júpiter e Vênus são candidatos em potencial e devem interferir muito sutilmente apenas gravitacionalmente. Mercúrio, Marte e Saturno, possível, mas pouco provável. Daí para adiante, você pode desconsiderar as interações existentes face às relações entre seu corpo e os objetos e outros seres humanos que te rodeiam na própria superfície da Terra.

\footnotetext{
${ }^{3} \mathrm{Ou}$, porque não determinam uma série de fatos com os quais lidamos cotidianamente.
} 


\section{Do ponto de vista do significado}

A discussão está longe de encerrada. Vamos a um exemplo elucidativo. Imagine que um estadista decida iniciar um bombardeio à capital do País vizinho a partir da leitura de seu horóscopo, que outro tome a mesma decisão lançando uma moedinha e um terceiro decida depois de refletir longamente e sem consultar ninguém. Seriam os três casos realmente diferentes?

No primeiro, há que reconhecer que o "mapa do céu" foi interpretado por alguém que escreveu as linhas do horóscopo. Ou seja, a relação entre a disposição dos astros e os sinais impressos na folha do jornal foi estabelecida por um ser humano. Certamente astrólogos diferentes não redigiriam textos equivalentes ${ }^{4}$. Por outro lado, o estadista leu 0 texto e associou seu conteúdo mental, ou seja, atribuiu um significado que certamente não é o mesmo daquele que redigiu as linhas e muito menos dos outros leitores. Ou seja, a decisão não dependeu do horóscopo, mas sim do arbítrio do estadista.
No segundo, há uma certa imponderabilidade, ou imprevisibilidade do resultado do lançamento da moedinha. A margem para interpretação parece ser muito pequena. Mas, entre 0 resultado e a decisão, sempre haverá a oportunidade de desrespeitar uma regra arbitrária que foi criada pelo próprio apostador. Ou seja, no limite, não importa o resultado do sorteio, a decisão continua sendo independente da moedinha, continua sendo essencialmente humana.

Finalmente, no terceiro caso, não há dúvida. A diferença deste para os outros dois, é que não houve um subterfúgio, não se jogou o peso da decisão para o imponderável ou para outrem. Estamos sempre às voltas com o livre arbítrio.

Evidentemente, esta discussão pode enveredar por considerações filosóficas mais rigorosas e profundas, mas, em nossa modesta opinião, inócuas para abordagem do problema junto aos alunos do ensino fundamental e médio.

\footnotetext{
${ }^{4}$ Supondo que um Astrólogo tenha mesmo se dado ao trabalho de interpretar mapas celestes e escrever o texto. Em alguns jornais, até alguns anos atrás, havia uma caixinha com centenas de fichas com textos genéricos. Todos os dias eram retiradas doze fichas ao azar. Copiava-se 0 texto para a edição do dia e depois de algumas semanas, recolocadas na caixinha, os textos voltavam a se repetir. Como a chance de um mesmo texto ser editado sob o mesmo signo do zodíaco num mesmo ano era quase nula, não se lê o horóscopo alheio a não ser o próprio e a memória humana não é tão sistemática quanto muitos pensam ser, era impossível perceber o expediente.
} 
AZEVEDO, T. R. (2006). THE ROLE OF STARS ON YOUR LIFE. Revista do Departamento de Geografia, n. 18, p. $42-47$.

Abstract: In the light of basic classic physics and astronomy knowledge, it is discussed if and how stars do really interfere in terrestrial processes on the scale of a human life. This is a didactic essay based on class content really gift on a Geography Teacher's Course.

Key words: Education; Geography; Astronomy; Gravitation.

Recebido em 20 de setembro de 2004, aceito em 2 de fevereiro de 2006.

\section{Referências}

ASIMOV, I. (1986) A medida do universo. Rio de janeiro, Francisco Alves.

BLOOM, A.L. (1970) Superfície da Terra. São Paulo, Editora Edgard Blücher Ltda.

BRODY, D.E.; BRODY, A.R. (1999) As sete maiores descobertas científicas da História. São Paulo, Companhia das Letras.

BRONOWSKI, J. (1983) A escala do homem. São Paulo, Martins Fontes.

CADOGAN, P. (1985) Lua nosso planeta irmão. Rio de janeiro,

\section{Francisco Alves.}

DANIKEN, E.V. (1970) De volta às estrelas. São Paulo, Companhia Melhoramentos.

HAWKING, S. (2001) O universo numa casca de noz. São Paulo, Mandarim.

MOURÃO, R.R.F. (1982) Em busca de outros mundos. Rio de Janeiro, Francisco Alves.

SAGAN, C. (1985) O romance da ciência. Rio de janeiro, Francisco Alves.

SAGAN, C. (1986) Cosmos. Rio de janeiro, Francisco Alves. 